\title{
Genotypic variation in response to extreme events may facilitate kelp adaptation under future climates
}

\author{
Nahlah A. Alsuwaiyan ${ }^{1,2}$, , Sofie Vranken ${ }^{1}$, Karen Filbee-Dexter ${ }^{1,3}$, \\ Marion Cambridge ${ }^{1}$, Melinda A. Coleman ${ }^{1,4,5}$, Thomas Wernberg ${ }^{1,3,6, *}$
}

\author{
${ }^{1}$ School of Biological Sciences and UWA Oceans Institute, University of Western Australia, Crawley, WA 6009, Australia \\ ${ }^{2}$ Department of Biology, Unaizah College of Sciences and Arts, Qassim University, Unaizah 51911, Kingdom of Saudi Arabia \\ ${ }^{3}$ Institute of Marine Research, His 4817, Norway \\ ${ }^{4}$ National Marine Science Centre, Southern Cross University, PO Box 4321, Coffs Harbour, NSW 2450, Australia \\ ${ }^{5}$ Department of Primary Industries, National Marine Science Centre, 2 Bay Drive, Coffs Harbor, NSW 2450, Australia \\ ${ }^{6}$ Department of Science and Environment, Roskilde University, Roskilde 4000, Denmark
}

\begin{abstract}
Marine heatwaves (MHWs) have caused declines in many kelp forests globally. Although the ecological effects of these climatic extremes have been well examined, studies on the role of genotypic variation in underpinning population responses under pressures are lacking. Understanding how kelps respond to different warming profiles and, in particular, intraspecific variation in responses is necessary to confidently anticipate the future of kelp forests, yet this remains a critical knowledge gap for most species. This study examined the responses of early life stages of 9 different genotypes of the Australian kelp Ecklonia radiata to different MHW profiles, where cumulative heat intensity was kept constant: control treatment (constant $19^{\circ} \mathrm{C}$ ), heat spikes (fluctuating $19-23^{\circ} \mathrm{C}$ ), low intensity MHW (ramp up $23^{\circ} \mathrm{C}$ ) and high intensity MHW (ramp up $27^{\circ} \mathrm{C}$ ). Overall, we found significant declines in E. radiata gametophyte performance in all MHW treatments and delays in sporophyte recruitment during MHW exposure. We also found significant genotype by environment (G×E) interactions, suggesting tolerance to acute thermal stress is influenced by genetic variation. Our results showed that offspring from different genotypes within the same population respond differently to MHWs, indicating that some genotypes are susceptible to MHWs while others are more resistant. While the effects on standing genetic variation and subsequent susceptibility to other stressors are unknown, our findings suggest that in addition to immediate impacts on marine organisms, natural genotypic variation in response to thermal anomalies may facilitate the gradual evolution of populations with increased thermal tolerance under future climates.
\end{abstract}

KEY WORDS: Genetic variation - Adaptation - Thermal reaction norms - Marine heatwave · Growth $\cdot$ Kelp $\cdot$ Ocean warming

\section{INTRODUCTION}

Extreme climatic events have driven rapid changes in species distributions and altered ecosystem structure and functioning by causing mortality, range shifts and community reconfiguration (Moreno \& Møller 2011, Smale et al. 2019). While the ecological consequences of extreme climatic events are well studied (e.g. Smale et al. 2019), less information is

\footnotetext{
*Corresponding author: thomas.wernberg@uwa.edu.au
}

available on the role of genetic diversity in enhancing population performance and ecosystem functions under stress, especially for marine systems (Wernberg et al. 2018). Yet these studies are necessary to reliably forecast species vulnerability and adaptive potential under future climate change.

Marine heatwaves (MHWs) are extreme events defined as sea surface temperature (SST) anomalies warmer than the $90^{\text {th }}$ percentile based on historical

() The authors 2021. Open Access under Creative Commons by Attribution Licence. Use, distribution and reproduction are unrestricted. Authors and original publication must be credited. 
observations from the prior $30 \mathrm{yr}$, which last for a period of 5 or more consecutive days (Hobday et al. 2016). In recent years, a number of high-profile MHWs have been recorded in all major ocean basins (Holbrook et al. 2019), with large ecological and socio-economic consequences (Smale et al. 2019). These extreme events have led to distributional shifts in benthic marine species and ecosystem reconfigurations (Smale \& Wernberg 2013, Wernberg et al. 2016, Oliver et al. 2017), including coral bleaching (Moore et al. 2012), loss of kelp forests (Wernberg et al. 2016, Arafeh-Dalmau et al. 2019, Rogers-Bennett \& Catton 2019, Thomsen et al. 2019, Filbee-Dexter et al. 2020), loss of seagrass meadows (Strydom et al. 2020) and extensive mortality of benthic marine invertebrates (Garrabou et al. 2009). These shortterm temperature extremes are predicted to increase in intensity, frequency and duration throughout the $21^{\text {st }}$ century as a consequence of climate change (Oliver et al. 2019, Laufkötter et al. 2020). Therefore, it is important to understand their impact on all levels of biological organization, from genes to ecosystems, in order to evaluate the ability of populations and species to adapt to future climates (Coleman \& Wernberg 2020, Coleman et al. 2020b, Gurgel et al. 2020).

Thermal stress not only drives local extinctions and range shifts (e.g. Wernberg et al. 2016, Arafeh-Dalmau et al. 2019), but can also lead to phenotypic plasticity or adaptation via directional selection that favours thermally tolerant genotypes (Coleman \& Wernberg 2020). Standing genetic variation among individuals plays a crucial role in the adaptability of a population, as higher genetic diversity provides a greater range of possible functional responses and increases the population's likelihood to withstand or overcome a stressor (Hughes \& Stachowicz 2004, Reusch et al. 2005, Wernberg et al. 2018). Therefore, adaptation towards increased tolerance of heat stress is only possible when the variability in heat tolerance is underpinned by genetic variation. On the other hand, extreme events such as MHWs might also cause an extreme loss in genetic diversity by eliminating less heat-tolerant genotypes (Gurgel et al. $2020)$, potentially reducing overall adaptive capacity to multiple future stressors (maladaptation).

Previous studies have examined the influence of genotypes on fitness to environmental stress in marine organisms (Császár et al. 2010, Pease et al. 2010, Foo et al. 2012), including genetic variation in thermal sensitivity among genotypes in kelp populations (Mabin et al. 2019, Liesner et al. 2020b). These studies have found heritable within-population variation for traits that influence the persistence of populations experiencing warming, suggesting that genetic variation may affect population resilience to heat stress. To robustly predict the long-term consequences of environmental stressors on natural populations, it is therefore important to move beyond simply measuring average population-level effects of a given thermal stress, and instead consider the variation in responses to stress among genotypes within populations (Clark et al. 2013, Coleman \& Wernberg 2020, Coleman \& Wernberg 2021).

Kelp have a biphasic-heteromorphic life cycle that alternates between microscopic haploid gametophyte stages and macroscopic diploid sporophytes (Fritsch 1942). These complex life-cycle stages differ in their thermal responses and survival limits (de Bettignies et al. 2018, Martins et al. 2020). For example, reproductive maturation (sporogenesis and gametogenesis) has a narrower temperature window than sporophyte and gametophyte growth and survival (Bartsch et al. 2013, Martins et al. 2017, de Bettignies et al. 2018), thus an increase in temperature may cause delays in reproductive development (de Bettignies et al. 2018, Martins et al. 2020). In addition, temperature tolerance thresholds vary between life stages, and gametophytes appear to withstand higher temperatures than young sporophytes (Bartsch et al. 2013, Martins et al. 2017). These microscopic stages influence recruitment success yet are extremely vulnerable to different environmental perturbations (e.g. Wiencke et al. 2006, Fredersdorf et al. 2009, Gaitán-Espitia et al. 2014, Borlongan et al. 2018). Gametophyte stages are thus particularly critical for the survival of kelp species in populations with significant sporophyte mortality due to extreme climatic events (Ladah \& Zertuche-González 2007, Barradas et al. 2011, Roleda \& Dethleff 2011).

Many studies have found that, under laboratory conditions, both life-cycle stages of kelp are severely impacted by heat stress and changes in water temperature. For example, high water temperature resulted in decreased sporophyte survival rates (Gao et al. 2016), substantial tissue deterioration (Andersen et al. 2013) and reduced kelp biomass by significantly decreasing growth rates and photosynthetic performances (Nepper-Davidsen et al. 2019). Effects on the microscopic stages included increased mortality of kelp zoospores and decreased germination rates (Gaitán-Espitia et al. 2014), reduced growth of gametophytes (Mohring et al. 2014) and limited fertilisation success (Oppliger et al. 2012). These studies suggest that responses may differ dramatically for each lifecycle stage under a warming climate scenario. Although the effect of heat stress on kelps has been well studied, the effect of increasing temperature 
variability, another characteristic of global change (Oliver et al. 2019), or how thermal stress is presented remains less understood. In general, only a few modelling studies have simulated environmental variability (e.g. pH) (Boyd et al. 2016), yet these variability stressors have been largely ignored in experiments.

Here, we investigated the responses of the early life stages of Australia's dominant underwater forestforming species, Ecklonia radiata (Wernberg et al. 2019), to different MHW profiles. We measured the performance of the haploid gametophyte and diploid sporophyte life stages of 9 different genotypes under constant temperature $\left(19^{\circ} \mathrm{C}\right)$, a low-magnitude heatwave $\left(23^{\circ} \mathrm{C}\right)$, a high-magnitude heatwave $\left(27^{\circ} \mathrm{C}\right)$ and highly variable temperature $\left(19-23^{\circ} \mathrm{C}\right)$ conditions. Treatments had an equal amount of cumulative heat intensity (sensu Hobday et al. 2016) in order to better understand if varying the way a consistent amount of thermal stress is delivered affected responses. By culturing different genotypes, we tested for genotype by environment interactions $(\mathrm{G} \times \mathrm{E})$ to determine whether there was within-population variation (genetic variation) in response to thermal stress (Clark et al. 2013).

\section{MATERIALS AND METHODS}

\subsection{Zoospore release and establishment of gametophyte cultures}

Nine fertile sporophytes of Ecklonia radiata (Laminariales) were haphazardly collected from $11 \mathrm{~m}$ depth by SCUBA divers from Hamelin Bay, Western Australia $\left(34^{\circ} 15^{\prime} 22.07^{\prime \prime} \mathrm{S}, 115^{\circ} 0^{\prime} 33.48^{\prime \prime} \mathrm{E}\right)$ in April 2019. The thalli were immediately transported to shore and processed for zoospore extraction following the methods of Alsuwaiyan et al. (2019). Briefly, sorus tissue was excised and sori were gently scraped, sterilised in a diluted iodine solution for $\sim 30 \mathrm{~s}$ to eliminate surface epiphytes, rinsed with $0.2 \mu \mathrm{m}$ filtered-autoclaved seawater, and excessive mucilage wiped away with clean paper towels. After cleaning, sori were stored between layers of moist tissue paper in darkness for $18 \mathrm{~h}$ at $10^{\circ} \mathrm{C}$. Zoospores were released the following day by immersing the sorus tissue in filtered, autoclaved seawater at $10^{\circ} \mathrm{C}$. Sori pieces from each sporophyte were placed into separate sterile beakers and covered with $100 \mathrm{ml}$ of seawater for zoospore release. Separate zoospore suspensions were sowed into Petri dishes and left undisturbed for $18 \mathrm{~h}$ at room temperature to allow the zoospores to settle. Sporophytes were confirmed to be unique genetic lines, as double digest restriction-site associated DNA sequencing (ddRAD) sequencing revealed samples to differ in $7-10 \%$ of loci (S. Vranken unpubl. data). These 9 unique genetic lines were followed separately throughout the experiment to assess differences in responses within and across life stages. After the settlement period, water in the Petri dishes was renewed with $0.2 \mu \mathrm{m}$ filtered-autoclaved seawater enriched with Provasoli solution (PES) (Provasoli 1968), with germanium dioxide $\left(\mathrm{GeO}_{2}\right)$ added to prevent diatom contamination (Lüning \& Neushul 1978). Culture medium was changed after $2 \mathrm{~d}$ and weekly from then on. Petri dishes were incubated in a controlled temperature room under the following culture conditions: $18^{\circ} \mathrm{C}, 6 \pm$ $3 \mu \mathrm{mol}$ photons $\mathrm{m}^{-2} \mathrm{~s}^{-1}$ red light, and $12 \mathrm{~h}$ light:12 h dark photoperiod. Red light was achieved by covering light tubes (Sylvania Luxline Plus FHO 24W/835) with red cellophane. When high gametophyte biomass had accumulated, Petri dishes were scraped using a sterilised cell scraper and the juvenile gametophytes were transferred into $250 \mathrm{ml}$ sterile cell culture flasks filled with $100 \mathrm{ml}$ PES. Gametophytes were maintained in a vegetative stage without aeration under the same conditions mentioned above. The PES medium was then renewed every $2 \mathrm{wk}$.

\subsection{Experimental design}

To create experimental treatments of gametophytes, healthy gametophyte mass from each of the 9 genetic lines were first broken down into shorter fragments using an electric blender ( $\mathrm{Li}$ et al. 2017) and then filtered through stacked mesh filters to select sizes in the range of 30-60 $\mu \mathrm{m}$ in length. This step was necessary to collect similar size gametophytes, allowing evaluation of treatment effects on gametophyte size. The fragments from each genotype $(n=9)$ were then sown into 16 labelled Petri dishes containing $\mathrm{PES}$, at an average density of $\sim 110$ fragments $\mathrm{ml}^{-1}$. Petri dishes were left in a controlled temperature room (set at $18^{\circ} \mathrm{C}, 6 \pm 3 \mu \mathrm{mol}$ photons $\mathrm{m}^{-2} \mathrm{~s}^{-1}$ red light, $12 \mathrm{~h}$ light: $12 \mathrm{~h}$ dark photoperiod) for $2 \mathrm{wk}$ to allow the gametophytes to settle. After $2 \mathrm{wk}$, PES medium was renewed and Petri dishes were moved to their respective treatments. There were 4 replicate Petri dishes per genotype in each treatment. Gametophytes were cultured under $50 \mu \mathrm{mol}$ photons $\mathrm{m}^{-2} \mathrm{~s}^{-1}$ with a photoperiod of $12 \mathrm{~h}$ light:12 h dark, and PES was replaced weekly. Four experimental treatments were used to test the effect of MHWs on gametophyte survival, growth and development (Fig. 1). In the control treatment, gameto- 


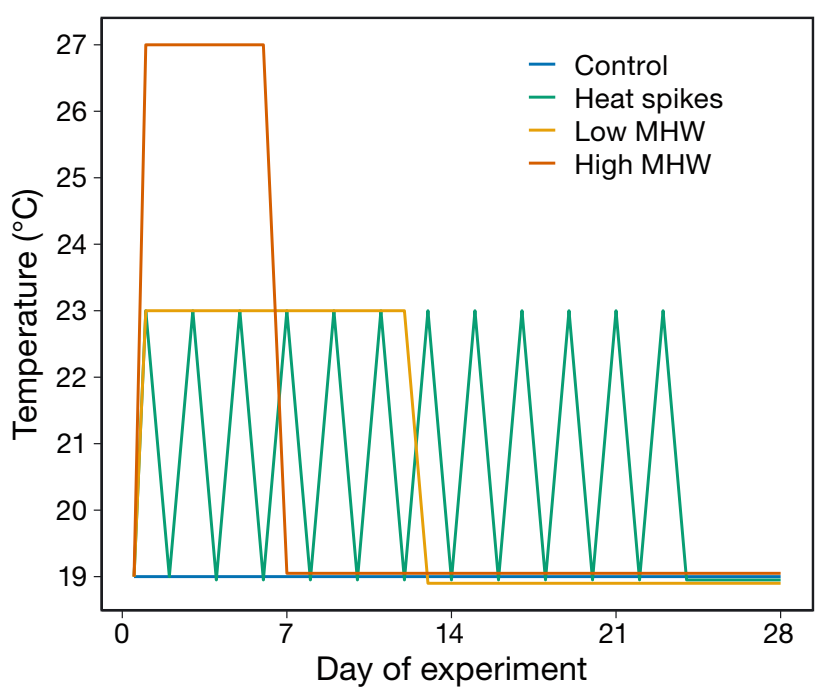

Fig. 1. Four culturing treatments of Ecklonia radiata gametophytes. Control: gametophytes cultured constantly at $19^{\circ} \mathrm{C}$; heat spikes: gametophytes cultured between 19 and $23^{\circ} \mathrm{C}$ for $23 \mathrm{~d}$ then constantly at $19^{\circ} \mathrm{C}$ for $5 \mathrm{~d}$; low intensity marine heat wave (MHW): gametophytes cultured at $23^{\circ} \mathrm{C}$ for $12 \mathrm{~d}$ then constantly at $19^{\circ} \mathrm{C}_{i}$ high intensity MHW: gametophytes cultured at $27^{\circ} \mathrm{C}$ for $6 \mathrm{~d}$ then constantly at $19^{\circ} \mathrm{C}$. All heat treatments have equal cumulative heat intensity $\left(48^{\circ} \mathrm{C}\right.$ cumulative intensity above the control)

phytes were cultured at a constant temperature of $19 \pm 0.5^{\circ} \mathrm{C}$, to represent ambient temperature conditions. Heat treatments were designed to have equal cumulative heat intensity $\left(48^{\circ} \mathrm{C}\right.$ cumulative intensity above the control). In the 'heat spikes' treatment, gametophytes were cultured at temperatures fluctuating between $19 \pm 0.5$ and $23 \pm 0.5^{\circ} \mathrm{C}$ every day for $23 \mathrm{~d}$, then back to $19 \pm 0.5^{\circ} \mathrm{C}$ for $5 \mathrm{~d}$. In the low and high MHW treatments, gametophytes were first cultured at $23 \pm 0.5^{\circ} \mathrm{C}$ for $12 \mathrm{~d}$ and $27 \pm 0.5^{\circ} \mathrm{C}$ for $6 \mathrm{~d}$, respectively, and back to $19 \pm 0.5^{\circ} \mathrm{C}$. We used $23^{\circ} \mathrm{C}$ for the low intensity MHW to represent the annual maximum SST during the Western Australia 2011 MHW (Wernberg et al. 2013), and $27^{\circ} \mathrm{C}$ for the high intensity MHW to represent the predicted more intense MHWs. Cultures were examined under a microscope on Days 1, 7, 14, 21 and 28 of the experiment, and 6 random fields of view (40x magnification) were photographed.

\subsection{Measurements}

From the photographs, the treatment effects were determined by measuring gametophyte survival, reproductive success (sporophyte density), size and relative growth rates (RGRs). Survivorship was deter- mined by counting the number of viable gametophytes over the initial density on Day 1. Viability of gametophytic cells was assessed by the presence of plastids with brown pigmentation (see inset of Fig. 2A) (Visch et al. 2019).

\subsubsection{Reproductive success (sporophyte density)}

Reproductive success was estimated following Lee \& Brinkhuis (1986):

Reproductive success $(\%)=[a /(a+b+c)] \times 100$

where $a$ is the number of female gametophytes bearing juvenile sporophytes, $b$ is the number of female gametophytes with oogonia and $c$ is the number of female gametophytes without oogonia.

\subsubsection{Size and RGR}

The size of gametophytes (maximum branch length) and juvenile sporophytes (thallus area) was recorded on Day 21 of culture and measured using ImageJ software. RGR $\mathrm{d}^{-1}$ was calculated using the following equation:

$$
\operatorname{RGR}\left(\% \mathrm{~d}^{-1}\right)=\left[\left(\ln L_{2}-\ln L_{1}\right) / t_{2}-t_{1}\right] \times 100
$$

where $L_{1}$ and $L_{2}$ are the lengths $\left(\mathrm{RGR}_{\mathrm{L}}\right)$ or widths $\left(\mathrm{RGR}_{\mathrm{W}}\right)$ at times $t_{1}$ and $t_{2}$ in days. Five male and 5 female gametophytes from every replicate dish were haphazardly selected and their maximum length measured on Day $1\left(t_{1}\right)$ and Day $21\left(t_{2}\right)$. For sporophyte measures, the 3 largest sporophytes from every replicate dish were selected and their maximum length and width measured on Day $21\left(t_{1}\right)$ and Day 28 $\left(t_{2}\right)$. Random sampling was avoided, since sporophytes that developed from eggs produced at different times could have been selected, obscuring real trends in growth rate (Kain 1965). For sporophytes, RGR was calculated for the thallus area $\left(\mathrm{RGR}_{\mathrm{A}}\right)$ as:

$$
\mathrm{RGR}_{\mathrm{A}}=\mathrm{RGR}_{\mathrm{L}}+\mathrm{RGR}_{\mathrm{W}}
$$

\subsection{Statistical analysis}

All analyses were performed in the $\mathrm{R}$ statistical environment version 4.0.0 (R Core Team 2020). We tested for significant differences in heat stress responses using ANOVA, with a significance level of $\alpha=0.05$. Normal distribution of standardized residuals was assessed using Shapiro-Wilks normality tests, while homogeneity of variance was tested using Lev- 
ene's test. Data were log transformed when the assumptions of normality and homogeneity of variance were not met (Underwood 1997). A 1-way ANOVA was performed to test for temperature treatment effects on density, size and RGR of gametophytes and sporophytes, with experimental temperature as a fixed factor with 4 levels. Separate analyses were conducted for population density at each time point (Day 7, 14 and 21 for gametophytes; Day 14, 21 and 28 for sporophytes). Day 28 was excluded from the gametophyte density analysis because the majority of gametophytes had undergone sporogenesis by this time. Day 7 was excluded from the sporophyte density analysis because sporophyte formation was near zero at the 3 heat treatments. There was no significant interaction between sex and experimental temperature on gametophyte size and RGR (size $\mathrm{p}=$ 0.954 , RGR $p=0.470$ ); therefore, sex was pooled for all gametophyte analyses (but see Fig. S1, Table S1 in the Supplement at www.int-res.com/articles/suppl/m672 p111_supp.pdf for analyses of both sexes separately). Pearson's correlations between traits were performed on genotype means to assess potential for intra- and inter-generational correlations. To determine the presence of genetic variation, a 2-way ANOVA was performed to test for the effects of genotype, experimental temperature and their interaction on density, size and RGR of gametophytes and sporophytes. Genotype was modelled as a random factor with 9 levels, whereas temperature treatment was modelled as a fixed factor with 4 levels. For all analyses, when ANOVA main tests yielded significant results, they were followed by Tukey's HSD post hoc tests.

\section{RESULTS}

\subsection{Population thermal tolerance}

Gametophyte densities showed a very pronounced, negative response to heat conditions over the experiment (Fig. 2A, Table S2 in the Supplement). Densities were lower in the 3 heat treatments compared to the control at all times in the experiment (Day $7 F_{3,32}=$ 8.25, p $<0.001$; Day $14 F_{3,32}=11.92, \mathrm{p}<0.001$; Day 21 $F_{3,32}=10.22, \mathrm{p}<0.001$; Table S2), but did not differ significantly among the heat treatments (Fig. 2A). Generally, gametophyte densities decreased over time to reach around $30-35 \%$ mortality rate across these heat treatments, compared to $20 \%$ mortality in the control (Fig. 2A). In contrast, temperature initially showed significant effects on sporophyte density
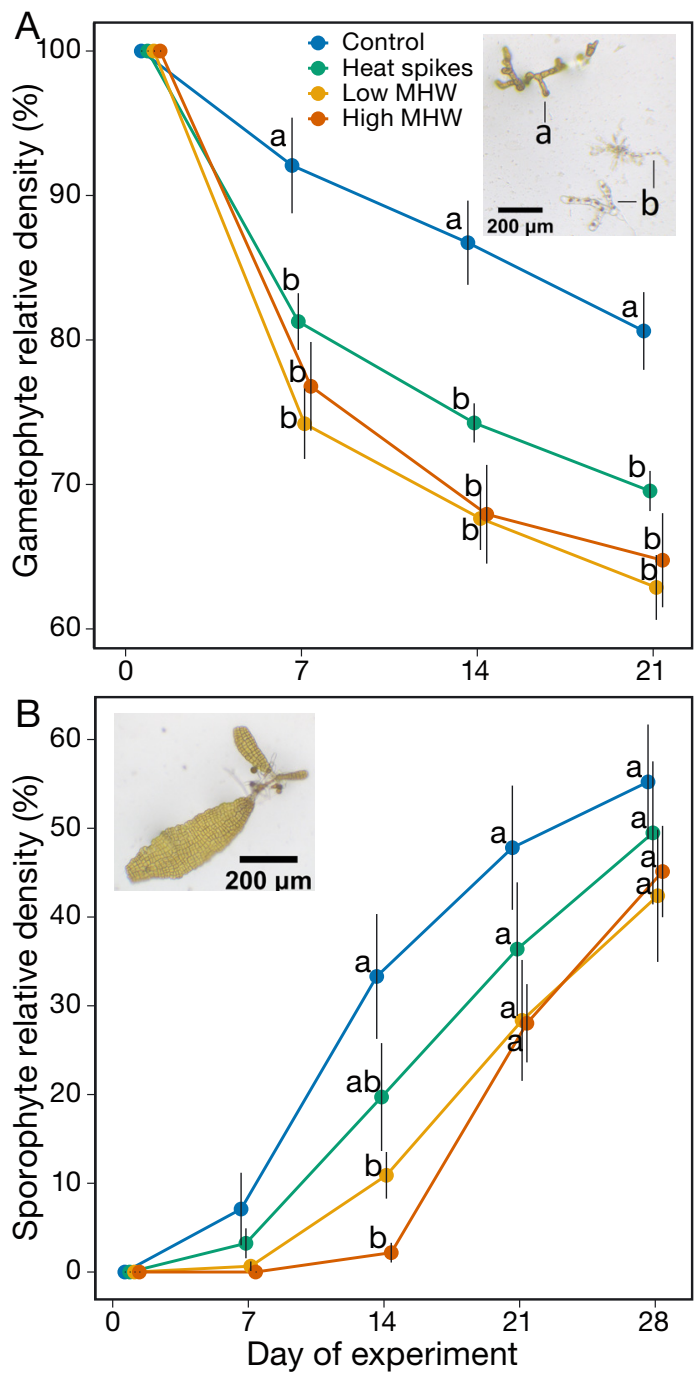

Fig. 2. Mean relative density $( \pm \mathrm{SE}, \mathrm{n}=9$ ) of Ecklonia radiata (A) gametophytes and (B) sporophytes over time. Gametophyte density was calculated by counting the number of viable gametophytes over the initial density on Day 1, whereas sporophyte density was calculated by counting the number of female gametophytes bearing juvenile sporophytes over the total number of female gametophytes observed. Different lowercase letters indicate significant differences between temperature treatments within time points (Tukey's HSD test, $\mathrm{p}<0.05$ ). Inset in (A) shows (a) viable gametophytic cells containing intact plastids with brown pigmentation and (b) lysed and non-viable gametophytic cells. Inset in (B) shows juvenile sporophytes

(Day $14 F_{3,32}=7.64, \mathrm{p}<0.001$; Fig. 2B, Table S2), with a delayed development of sporophyte observed in the low and high MHW treatments. However, with longer recovery time, post MHW, sporophyte densities increased to reach around $45 \%$ by the end of the experiment (Fig. 2B). Notably, densities on Day 14 were not statistically significant between the control and heat spikes, or among the 3 heat treatments (Fig. 2B). 

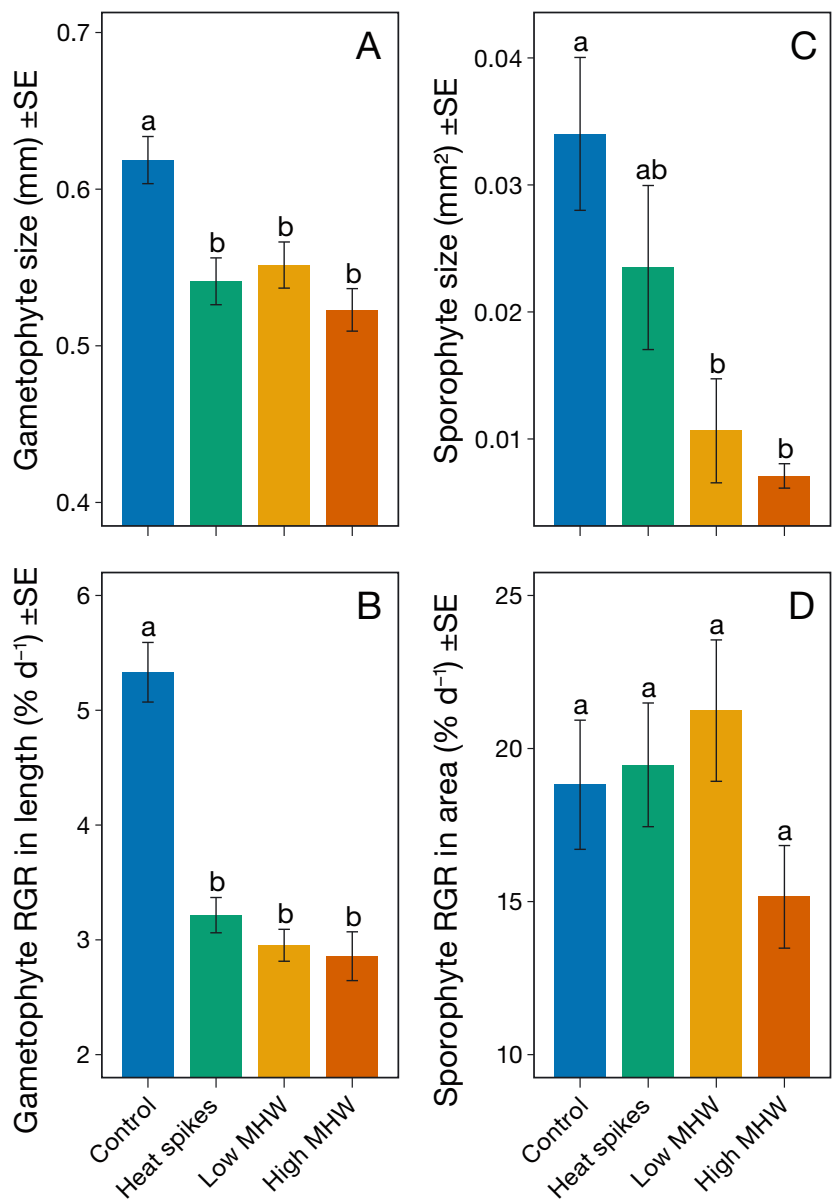

Fig. 3. Mean size and relative growth rate (RGR) $( \pm \mathrm{SE}, \mathrm{n}=9$ ) of Ecklonia radiata $(\mathrm{A}, \mathrm{B})$ gametophytes and $(\mathrm{C}, \mathrm{D})$ sporophytes. Different lowercase letters indicate significant differences between temperature treatments (Tukey's HSD test, $\mathrm{p}<0.05)$

Heat treatments negatively affected both gametophyte size $\left(F_{3,32}=8.00, \mathrm{p}<0.001\right.$; Fig. 3A, Table S3 in the Supplement) and RGR $\left(F_{3,32}=35.28, \mathrm{p}<0.001\right.$; Fig. 3B, Table S3). Size and RGR, in the control treatment, averaged $0.62 \mathrm{~mm}$ and $5.33 \% \mathrm{~d}^{-1}$, respectively, and both decreased significantly with the 3 heat treatments, but with no significant difference in mean values among the heat treatments (Fig. 3A,B). Similarly, sporophyte size was susceptible to the heat treatments $\left(F_{3,32}=6.18, \mathrm{p}=0.002\right.$; Fig. 3C, Table S3), but not RGR $\left(F_{3,32}=1.57, \mathrm{p}=0.216\right.$; Fig. 3D, Table S3). Sporophyte size was significantly larger in the control $\left(0.034 \mathrm{~mm}^{2}\right)$ than in the $2 \mathrm{MHW}$ treatments, however, size did not vary between the control and heat spikes. Among the heat treatments, heat spikes led to larger sporophytes, and size decreased by around $75 \%$ in the high MHW treatment, though these differences were not significant (Fig. 3C).
Pearson's r correlation showed no significant correlation between gametophyte density and sporophyte density in any of the 4 experimental treatments (Fig. S2A-D in the Supplement), nor between gametophyte size and gametophyte density (Fig. S2E-H). However, sporophyte size was significantly correlated with sporophyte density (Fig. S2I-L).

\subsection{Interactive effects of genotype}

MHWs affected density and growth patterns of Ecklonia radiata early life stages, but the magnitude of responses to the stressful temperatures were dependent on genotypes as well (Fig. 4, Table 1; for reaction norms across all 4 temperature treatments see Fig. S3 in the Supplement). There was a significant $\mathrm{G} \times \mathrm{E}$ interaction in gametophyte size $\left(F_{24,108}=2.52\right.$, $\mathrm{p}<0.001$; Fig. 4B, Table 1$)$ and RGR $\left(F_{24,108}=2.22, \mathrm{p}=\right.$ 0.003; Fig. 4C, Table 1), indicating that genotypes differed in their plastic response to temperature. Sporophyte density (Fig. 4D) and size (Fig. 4E) also showed the same pattern of genetic variation for plasticity with the significant $\mathrm{G} \times \mathrm{E}$ interaction (density $F_{24,108}=$ $2.14, \mathrm{p}=0.004$; size $F_{24,108}=2.64, \mathrm{p}<0.001$; Table 1 ). The observed thermal reaction norms showed changes in the ranking of genotypes across temperature treatments in each of the 4 response variables; however, for gametophyte RGR and sporophyte size, the magnitude of inter-genotypic variance decreased in the high MHW treatment (Fig. 4). For sporophyte RGR, reaction norm slopes were more similar, but still differed in magnitude $\left(F_{8,108}=8.29, \mathrm{p}<0.001\right.$; Fig. $4 \mathrm{~F}_{\text {, }}$ Table 1). Together, these results show that the impacts of the MHW treatments on E. radiata early life stages are highly variable among genotypes.

\section{DISCUSSION}

Climatic extremes (i.e. MHWs) have caused devastating effects on marine ecosystems with significant ecological and socio-economic consequences (Smale et al. 2019), in particular loss of kelp forests (Wernberg et al. 2016, Arafeh-Dalmau et al. 2019, RogersBennett \& Catton 2019, Thomsen et al. 2019, FilbeeDexter et al. 2020) and erosion of their adaptive capacity (Coleman et al. 2020a, Gurgel et al. 2020). The effects of MHWs on populations are strongly related to genetic diversity among populations (Wernberg et al. 2018). In our study, we found that MHWs significantly reduced Ecklonia radiata gametophyte performance and delayed sporophyte recruitment. 

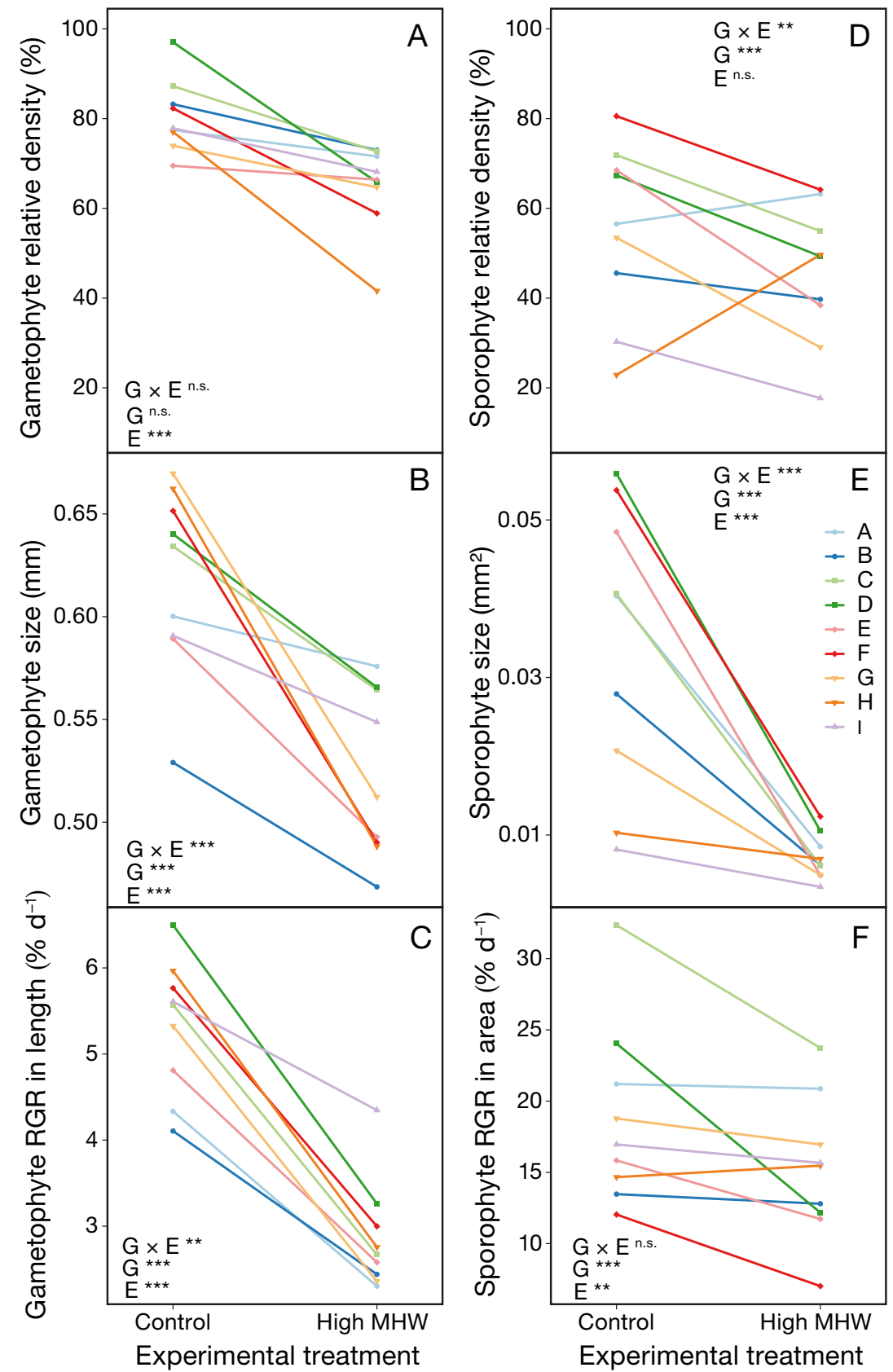

Fig. 4. Reaction norms for density and growth patterns of Ecklonia radiata (A-C) gametophytes and (D-F) sporophytes to visualize genetic variation in plasticity among genotypes. Lines represent the contrast between the means of each genotype. Statistical significance of the factors for genotype (G), experimental treatment $(\mathrm{E})$ and $\mathrm{G}$ by $\mathrm{E}$ interaction $(\mathrm{G} \times \mathrm{E})$ is summarised: ${ }^{* * *} \mathrm{p}<$ $0.001 ;{ }^{* *} \mathrm{p}<0.01{ }^{*}{ }^{*} \mathrm{p}<0.05$; ns: not significant. For full statistical report see Table 1. For reaction norms across all 4 temperature treatments see Fig. S3 in the Supplement

We also found some variation in thermal tolerance linked to genetic variation, as indicated by the significant G×E interaction, suggesting the presence of heritable variation in tolerance to thermal stress.

\subsection{General temperature effects}

High water temperatures generally result in a decline in gametophyte growth and survival (Mohring et al. 2014, Shukla \& Edwards 2017), because temperature-induced damage to kelp often negatively affects physiological performance (i.e. growth and photosynthesis) (Borlongan et al. 2018). We found that $E$. radiata gametophytes were negatively affected by heat spikes and the 2 MHW treatments. This result is not surprising, given that E. radiata gametophytes can survive and grow in temperatures from 12$26^{\circ} \mathrm{C}$ but experience a decline in growth and survival outside the 18$23^{\circ} \mathrm{C}$ range (Mohring et al. 2014). Our results match other studies which found that $E$. radiata gametophytes could grow in temperatures up to $25^{\circ} \mathrm{C}$ but growth decreased by $>50 \%$ above $22^{\circ} \mathrm{C}$ (e.g. Mabin et al. 2013), suggesting that gametophytes may have undergone heat-related damage. The most important finding in our study was, however, that different heat treatments (heat spikes, low MHW and high MHW) had similarly negative effects on gametophytes. Given that all 3 heat treatments had equal cumulative heat intensity, this observation suggests that gametophyte survival, size and RGR may be more influenced by total heat exposure rather than specific warming profiles of heat intensity. While a ramp up to $+8^{\circ} \mathrm{C}$ in a day, as in our temperature treatments, is unlikely or rare in this system, fluctuations of $3-5^{\circ} \mathrm{C}$ within $4-$ $24 \mathrm{~h}$ occur regularly (see Smale \& Wernberg 2009). Still, the observed response in gametophyte performance across the 3 heat treatments may be a response to an instantaneous heat shock rather than the mode of our heat treatments. Further, the use of PES in our experiments may have contributed to the observed results; larger effects might have been observed with the use of ambient seawater, where nitrogen is less available. Previous studies have found that nitrogen modulates kelp thermal 
Table 1. ANOVA main test results testing for the effect of genotype $\left(G_{\text {; }}\right.$ random factor), experimental temperature ( $\mathrm{E}$; fixed factor) and their interaction (G×E) on density, size and relative growth rate (RGR) of Ecklonia radiata gametophytes and sporophytes. Significant results $(p<0.05)$ are highlighted bold. Sporophyte size data were transformed to meet the assumptions of ANOVA (before log transformation: $p<0.01$; after log transformation: $\mathrm{p}=0.162$ )

\begin{tabular}{|c|c|c|c|c|c|c|c|}
\hline \multirow{2}{*}{$\begin{array}{l}\text { Source of } \\
\text { variation }\end{array}$} & \multirow{2}{*}{ df } & \multicolumn{3}{|c|}{ Gametophytes } & \multicolumn{3}{|c|}{ Sporophytes } \\
\hline & & MS & $F$ & $\mathrm{p}$ & MS & $F$ & $\mathrm{p}$ \\
\hline \multicolumn{8}{|l|}{ Density } \\
\hline $\mathrm{G}$ & 8 & 292.29 & 1.46 & 0.182 & 5032.11 & 18.31 & $<0.001$ \\
\hline E & 3 & 2282.03 & 11.40 & $<0.001$ & 1128.67 & 1.92 & 0.154 \\
\hline $\mathrm{G} \times \mathrm{E}$ & 24 & 200.26 & 1.00 & 0.475 & 588.38 & 2.14 & 0.004 \\
\hline Residual & 108 & 200.61 & & & 274.84 & & \\
\hline \multicolumn{8}{|l|}{ Size } \\
\hline $\mathrm{G}$ & 8 & 0.01 & 5.79 & $<0.001$ & 1.77 & 24.27 & $<0.001$ \\
\hline E & 3 & 0.06 & 10.83 & $<0.001$ & 3.73 & 19.41 & $<0.001$ \\
\hline $\mathrm{G} \times \mathrm{E}$ & 24 & 0.01 & 2.52 & $<0.001$ & 0.19 & 2.64 & $<0.001$ \\
\hline Residual & 108 & 0.00 & & & 0.07 & & \\
\hline \multicolumn{8}{|l|}{ RGR } \\
\hline G & 8 & 2.53 & 5.50 & $<0.001$ & 425.75 & 8.29 & $<0.001$ \\
\hline $\mathrm{E}$ & 3 & 49.38 & 48.32 & $<0.001$ & 247.20 & 4.66 & 0.011 \\
\hline $\mathrm{G} \times \mathrm{E}$ & 24 & 1.02 & 2.22 & 0.003 & 53.03 & 1.03 & 0.433 \\
\hline Residual & 108 & 0.46 & & & 51.34 & & \\
\hline
\end{tabular}

fertilization had occurred (Mabin et al. 2013). Moreover, maternal links may exist between life stages, affecting recruitment phenotype (Allen \& Marshall 2013), and can also determine early offspring fitness under stressful conditions (Marshall 2008). However, maternal effects do not always persist across life-history stages (Allen \& Marshall 2014) and so are not necessarily a strong indicator of adult fitness. In our study, we found no correlations between the 2 life-history stages.

A significant finding in our study is that sporophyte production was not suppressed during the heat spike treatments, with no significant differences in sporophyte density between heat spikes and the control. This result suggests that while prolonged periods of high heat are a key limitation to reproduction, heat stress that includes even short periods of more optimal temperatures, as in the heat spikes treatment, are enough to maintain reproduction. In addition, sporophyte RGRs did not differ be-

plasticity, alleviating the negative effects of high seawater temperatures on kelp growth and photosynthesis (Fernández et al. 2020), although this may be species-specific.

Reproductive success was affected by MHWs, as gametophytes delayed development of sporophytes during the MHW exposure days. This may reflect a mechanism by which gametophytes under non-lethal conditions, such as high but sub-lethal temperatures, have the ability to remain in a dormant or suppressed growth state for extended periods until conditions become favourable for growth and recruitment (Carney \& Edwards 2010, Schoenrock et al. 2021), and this may be a trait that enables rapid recovery from stress. This prolonged vegetative growth of gametophytes may also result in gametophytes developing more female cells, which may potentially develop into oogonia, thus increasing sporophyte recruitment (Bolton \& Levitt 1985, Liesner et al. 2020b). In our experiment, recovery occurred subsequently and sporophyte density almost reached that of controls by the end of the experiment. Thus, sub-lethal effects of MHWs on kelp gametophyte may be transient, with maturation and sporophyte recruitment resuming as soon as favourable environmental conditions prevail.

The absence of sporophytes during the MHW days, however, does not necessarily mean that sporophytes are incapable of surviving and growing at these temperatures but could instead indicate that no effective tween temperature treatments at all, whereas size declined in the $2 \mathrm{MHW}$ treatments and was significantly correlated with sporophyte density. This correlation could explain the patterns in size observed in our study, where the delayed development of sporophytes during the MHW exposure days may have resulted in younger and subsequently smaller sporophytes.

\section{2. $\mathrm{G} \times \mathrm{E}$ interactions}

Genotypic variation in stress tolerance may provide resilience to future climate change in species and populations as it allows adaptive responses to occur (Wernberg et al. 2018). Our thermal reaction norm results showed that genotypes differed in their susceptibility to MHWs in both life-history stages. The significant $\mathrm{G} \times \mathrm{E}$ interactions observed indicate that the tested genotypes might differ in their thermal plasticity or have inherent genetic variation related to temperature tolerance. From the reaction norms, it is clear that MHW decreased the magnitude of intergenotypic variance among genotypes in some response traits (i.e. gametophyte RGR and sporophyte size), but the ranking order of genotypes still changed across temperature treatments. This indicates variation in genotype responses to the MHW treatment, which coincides with emerging evidence suggesting that variation in stress tolerance among different 
genotypes can contribute to the magnitude of response to extreme events (Wernberg et al. 2018, Coleman \& Wernberg 2020, 2021, Coleman et al. 2020a, Gurgel et al. 2020). Previous studies on thermal reaction norms have also shown G×E interactions, indicating variation in temperature tolerance among genotypes (Clark et al. 2013, Mabin et al. 2019, Liesner et al. 2020b). For example, Mabin et al. (2019) found significant morphological variation in $E$. radiata gametophytes from different lineages in response to different temperature and light levels, which they linked to possible maternal and genetic effects. Thus, selection for more tolerant genotypes may lead to the gradual evolution of populations with increased thermal tolerance.

Furthermore, genetic variation is an important characteristic for natural selection in populations under stressful conditions (Chevin et al. 2010, Kelly 2019) that could have substantial effects on the adaptive capacity of kelp populations in a warming environment (Coleman \& Wernberg 2020, 2021, Vranken et al. 2021). Indeed, understanding $G \times E$ interactions is key to identifying the relations between stress, plasticity and adaptive evolutionary potential within populations (Liesner et al. 2020b). Gene flow is one process that could increase or decrease the magnitude of $\mathrm{G} \times \mathrm{E}$ interactions, and with the limited dispersal capacity in kelp populations and low amounts of gene flow from distant populations, this could facilitate local adaptation (King et al. 2018, Liesner et al. 2020a, Miller et al. 2020, Vranken et al. 2021) and potentially maladaptation. MHWs may, however, be too extreme for local adaptation and instead lead to massive and cryptic loss of genetic diversity within populations (Gurgel et al. 2020) that may compromise their longer-term ability to respond to change. Indeed, such losses of genetic diversity have been observed in kelp populations following an extreme MHW event (e.g. up to $66 \%$ loss of genetic diversity in Scytothalia dorycarpa), which surpasses loss of genetic diversity after extreme events in comparison to terrestrial species (e.g. 10-14\% average loss) (Jangjoo et al. 2016, Poff et al. 2018).

\section{CONCLUSIONS}

Extreme warming events can have devastating effects on kelp forests, with response (Wernberg et al. 2018) and recovery determined by genetic diversity (Coleman \& Wernberg 2020, Coleman et al. 2020a, Gurgel et al. 2020, Vranken et al. 2021). Overall, we found that warming events (i.e. heat spikes and
MHWs) significantly affected the development of Ecklonia radiata early life stages. Notably, we found no differences in gametophyte performance among the different MHW profiles, implying that response to thermal stress might be dependent on total heat exposure rather than specific profiles of heat intensity. However, temperature is only one factor in a complex multi-stressor environment, and other environmental stressors may modify a population's ability to tolerate extreme events.

We also found some evidence for consistent variation in thermal tolerance among genotypes from a single population, suggesting the presence of heritable variation in tolerance to thermal stress. This ability to respond to stress will likely increase when inter-population differences are taken into account (Clark et al. 2013). Therefore, to robustly predict the ecophysiological response of kelp populations to extreme events, future studies should account for genotypic variation in heat response within and between populations. Moreover, by designing strategies such as restoration to recover lost or declining kelp populations, we may be able to harness intrapopulation genetic variation in thermal response to boost the resilience of populations to climate change.

Acknowledgements. This study was funded by the Australian Research Council through funding to T.W., M.A.C. (DP160100114) and T.W., M.A.C. and K.F.D. (DP190100058), a postgraduate scholarship from Qassim University, Kingdom of Saudi Arabia to N.A.A., and a Robson and Robertson PhD Award to N.A.A. and S.V.

\section{LITERATURE CITED}

Allen RM, Marshall DJ (2013) Phenotypic links among lifehistory stages are complex and context-dependent in a marine invertebrate: interactions among offspring size, larval nutrition and postmetamorphic density. Funct Ecol 27:1358-1366

Allen RM, Marshall D (2014) Egg size effects across multiple life-history stages in the marine annelid Hydroides diramphus. PLOS ONE 9:e102253

Alsuwaiyan NA, Mohring MB, Cambridge M, Coleman MA, Kendrick GA, Wernberg T (2019) A review of protocols for the experimental release of kelp (Laminariales) zoospores. Ecol Evol 9:8387-8398

Andersen GS, Foldager Pedersen M, Nielsen SL (2013) Temperature acclimation and heat tolerance of photosynthesis in Norwegian Saccharina latissima (Laminariales, Phaeophyceae). J Phycol 49:689-700

Arafeh-Dalmau N, Montaño-Moctezuma G, Martínez JA, Beas-Luna R, Schoeman DS, Torres-Moye G (2019) Extreme marine heatwaves alter kelp forest community near its equatorward distribution limit. Front Mar Sci 6:499

Barradas A, Alberto F, Engelen A, Serrao E (2011) Fast sporophyte replacement after removal suggests banks of latent 
microscopic stages of Laminaria ochroleuca (Phaeophyceae) in tide pools in northern Portugal. Cah Biol Mar 52:435-439

* Bartsch I, Vogt J, Pehlke C, Hanelt D (2013) Prevailing sea surface temperatures inhibit summer reproduction of the kelp Laminaria digitata at Helgoland (North Sea). J Phycol 49:1061-1073

Bolton JJ, Levitt GJ (1985) Light and temperature requirements for growth and reproduction in gametophytes of Ecklonia maxima (Alariaceae: Laminariales). Mar Biol 87:131-135

Borlongan IA, Matsumoto K, Nakazaki Y, Shimada N and others (2018) Photosynthetic activity of two life history stages of Costaria costata (Laminariales, Phaeophyceae) in response to PAR and temperature gradient. Phycologia 57:159-168

* Boyd PW, Cornwall CE, Davison A, Doney SC and others (2016) Biological responses to environmental heterogeneity under future ocean conditions. Glob Change Biol 22:2633-2650

Carney LT, Edwards MS (2010) Role of nutrient fluctuations and delayed development in gametophyte reproduction by Macrocystis pyrifera (Phaeophyceae) in Southern California. J Phycol 46:987-996

Chevin LM, Lande R, Mace GM (2010) Adaptation, plasticity, and extinction in a changing environment: towards a predictive theory. PLOS Biol 8:e1000357

* Clark JS, Poore AGB, Ralph PJ, Doblin MA, Harley C (2013) Potential for adaptation in response to thermal stress in an intertidal macroalga. J Phycol 49:630-639

* Coleman MA, Wernberg T (2020) The silver lining of extreme events. Trends Ecol Evol 35:1065-1067

* Coleman MA, Wernberg T (2021) A glass half full: solutionsoriented management under climate change. Trends Ecol Evol 36:385-386

* Coleman MA, Minne AJP, Vranken S, Wernberg T (2020a) Genetic tropicalisation following a marine heatwave. Sci Rep 10:12726

Coleman MA, Wood G, Filbee-Dexter K, Minne AJP and others (2020b) Restore or redefine: future trajectories for restoration. Front Mar Sci 7:237

* Császár NBM, Ralph PJ, Frankham R, Berkelmans R, van Oppen MJH (2010) Estimating the potential for adaptation of corals to climate warming. PLOS ONE 5:e9751

de Bettignies T, Wernberg T, Gurgel CFD (2018) Exploring the influence of temperature on aspects of the reproductive phenology of temperate seaweeds. Front Mar Sci 5: 218

Fernández PA, Gaitán-Espitia JD, Leal PP, Schmid M, Revill AT, Hurd CL (2020) Nitrogen sufficiency enhances thermal tolerance in habitat-forming kelp: implications for acclimation under thermal stress. Sci Rep 10:3186

Filbee-Dexter K, Wernberg T, Grace SP, Thormar J and others (2020) Marine heatwaves and the collapse of marginal North Atlantic kelp forests. Sci Rep 10:13388

Foo SA, Dworjanyn SA, Poore AGB, Byrne M (2012) Adaptive capacity of the habitat modifying sea urchin Centrostephanus rodgersii to ocean warming and ocean acidification: performance of early embryos. PLOS ONE 7:e42497

*Fredersdorf J, Müller R, Becker S, Wiencke C, Bischof K (2009) Interactive effects of radiation, temperature and salinity on different life history stages of the Arctic kelp Alaria esculenta (Phaeophyceae). Oecologia 160:483-492

Fritsch FE (1942) Studies in the comparative morphology of the algae II: the algal life-cycle. Ann Bot 6:533-563
Gaitán-Espitia JD, Hancock JR, Padilla-Gamiño JL, Rivest EB, Blanchette CA, Reed DC, Hofmann GE (2014) Interactive effects of elevated temperature and $\mathrm{pCO}_{2}$ on early-life-history stages of the giant kelp Macrocystis pyrifera. J Exp Mar Biol Ecol 457:51-58

Gao X, Endo H, Nagaki M, Agatsuma Y (2016) Growth and survival of juvenile sporophytes of the kelp Ecklonia cava in response to different nitrogen and temperature regimes. Fish Sci 82:623-629

*Garrabou J, Coma R, Bensoussan N, Bally M and others (2009) Mass mortality in Northwestern Mediterranean rocky benthic communities: effects of the 2003 heat wave. Glob Change Biol 15:1090-1103

* Gurgel CFD, Camacho O, Minne AJP, Wernberg T, Coleman MA (2020) Marine heatwave drives cryptic loss of genetic diversity in underwater forests. Curr Biol 30:1199-1206

*Hobday A, Alexander L, Perkins-Kirkpatrick S, Smale D and others (2016) A hierarchical approach to defining marine heatwaves. Prog Oceanogr 141:227-238

*Holbrook NJ, Scannell HA, Alexander Sen G, Benthuysen JA and others (2019) A global assessment of marine heatwaves and their drivers. Nat Commun 10:2624

*Hughes AR, Stachowicz JJ (2004) Genetic diversity enhances the resistance of a seagrass ecosystem to disturbance. Proc Natl Acad Sci USA 101:8998-9002

* Jangjoo M, Matter SF, Roland J, Keyghobadi N (2016) Connectivity rescues genetic diversity after a demographic bottleneck in a butterfly population network. Proc Natl Acad Sci USA 113:10914-10919

Kain JM (1965) Aspects of the biology of Laminaria hyperborea IV. Growth of early sporophytes. J Mar Biol Assoc UK 45:129-143

Kelly M (2019) Adaptation to climate change through genetic accommodation and assimilation of plastic phenotypes. Philos Trans R Soc B 374:20180176

K King NG, McKeown NJ, Smale DA, Moore PJ (2018) The importance of phenotypic plasticity and local adaptation in driving intraspecific variability in thermal niches of marine macrophytes. Ecography 41:1469-1484

* Ladah LB, Zertuche-González JA (2007) Survival of microscopic stages of a perennial kelp (Macrocystis pyrifera) from the center and the southern extreme of its range in the Northern Hemisphere after exposure to simulated El Niño stress. Mar Biol 152:677-686

*LLaufkötter C, Zscheischler J, Frölicher TL (2020) Highimpact marine heatwaves attributable to human-induced global warming. Science 369:1621-1625

* Lee JA, Brinkhuis BH (1986) Reproductive phenology of Laminaria saccharina (L.) Lamour. (Phaeophyta) at the southern limit of its distribution in the nothwestern Atlantic Ocean. J Phycol 22:276-285

* Li J, Pang S, Shan T (2017) Existence of an intact male life cycle offers a novel way in pure-line crossbreeding in the brown alga Undaria pinnatifida. J Appl Phycol 29:993-999

*Liesner D, Fouqueau L, Valero M, Roleda MY and others (2020a) Heat stress responses and population genetics of the kelp Laminaria digitata (Phaeophyceae) across latitudes reveal differentiation among North Atlantic populations. Ecol Evol 10:9144-9177

Liesner D, Shama LNS, Diehl N, Valentin K, Bartsch I (2020b) Thermal plasticity of the kelp Laminaria digitata (Phaeophyceae) across life cycle stages reveals the importance of cold seasons for marine forests. Front Mar Sci 7:456

* Lüning K, Neushul M (1978) Light and temperature demands for growth and reproduction of laminarian ga- 
metophytes in southern and central California. Mar Biol 45:297-309

Mabin CJT, Gribben PE, Fischer A, Wright JT (2013) Variation in the morphology, reproduction and development of the habitat-forming kelp Ecklonia radiata with changing temperature and nutrients. Mar Ecol Prog Ser 483:117-131

Mabin CJT, Johnson CR, Wright JT (2019) Family-level variation in early life-cycle traits of kelp. J Phycol 55:380-392

* Marshall DJ (2008) Transgenerational plasticity in the sea: context-dependent maternal effects across the life history. Ecology 89:418-427

* Martins N, Tanttu H, Pearson GA, Serrão EA, Bartsch I (2017) Interactions of daylength, temperature and nutrients affect thresholds for life stage transitions in the kelp Laminaria digitata (Phaeophyceae). Bot Mar 60:109-121

Martins N, Pearson GA, Bernard J, Serrão EA, Bartsch I (2020) Thermal traits for reproduction and recruitment differ between Arctic and Atlantic kelp Laminaria digitata. PLOS ONE 15:e0235388

Miller AD, Coleman MA, Clark J, Cook R and others (2020) Local thermal adaptation and limited gene flow constrain future climate responses of a marine ecosystem engineer. Evol Appl 13:918-934

Mohring MB, Wernberg T, Wright JT, Connell SD, Russell BD (2014) Biogeographic variation in temperature drives performance of kelp gametophytes during warming. Mar Ecol Prog Ser 513:85-96

Moore JAY, Bellchambers LM, Depczynski MR, Evans RD and others (2012) Unprecedented mass bleaching and loss of coral across $12^{\circ}$ of latitude in Western Australia in 2010-11. PLOS ONE 7:e51807

Moreno J, Møller AP (2011) Extreme climatic events in relation to global change and their impact on life histories. Curr Zool 57:375-389

Nepper-Davidsen J, Andersen DT, Pedersen M (2019) Exposure to simulated heatwave scenarios causes long-term reductions in performance in Saccharina latissima. Mar Ecol Prog Ser 630:25-39

Oliver ECJ, Benthuysen JA, Bindoff NL, Hobday AJ, Holbrook NJ, Mundy CN, Perkins-Kirkpatrick SE (2017) The unprecedented 2015/16 Tasman Sea marine heatwave. Nat Commun 8:16101

Oliver ECJ, Burrows MT, Donat MG, Sen Gupta A and others (2019) Projected marine heatwaves in the $21^{\text {st }}$ century and the potential for ecological impact. Front Mar Sci 6:734

* Oppliger LV, Correa JA, Engelen AH, Tellier F and others (2012) Temperature effects on gametophyte life-history traits and geographic distribution of two cryptic kelp species. PLOS ONE 7:e39289

* Pease CJ, Johnston EL, Poore AGB (2010) Genetic variability in tolerance to copper contamination in a herbivorous marine invertebrate. Aquat Toxicol 99:10-16

Poff NL, Larson EI, Salerno PE, Morton SG and others (2018) Extreme streams: species persistence and genomic change in montane insect populations across a flooding gradient. Ecol Lett 21:525-535

Provasoli L (1968) Media and prospects for the cultivation of marine algae. In: Watanabe A, Hattori A (eds) Cultures and collections of algae. Proceedings of the US-Japan Conference, 12-15 September 1966. Japanese Society of Plant Physiology, Hakone, p 63-75

* Core Team (2020). R: A language and environment for statistical computing. R Foundation for Statistical Computing, Vienna

Editorial responsibility: Jean-Sébastien Lauzon-Guay, Dartmouth, Nova Scotia, Canada

Reviewed by: P. Moore and 1 anonymous referee
Reusch TBH, Ehlers A, Hämmerli A, Worm B (2005) Ecosystem recovery after climatic extremes enhanced by genotypic diversity. Proc Natl Acad Sci USA 102:2826-2831

* Rogers-Bennett L, Catton CA (2019) Marine heat wave and multiple stressors tip bull kelp forest to sea urchin barrens. Sci Rep 9:15050-15059

Koleda MY, Dethleff D (2011) Storm-generated sediment deposition on rocky shores: simulating burial effects on the physiology and morphology of Saccharina latissima sporophytes. Mar Biol Res 7:213-223

Schoenrock KM, McHugh TA, Krueger-Hadfield SA, Edwards M (2021) Revisiting the 'bank of microscopic forms' in macroalgal-dominated ecosystems. J Phycol 57: $14-29$

Shukla P, Edwards MS (2017) Elevated $\mathrm{pCO}_{2}$ is less detrimental than increased temperature to early development of the giant kelp, Macrocystis pyrifera (Phaeophyceae, Laminariales). Phycologia 56:638-648

* Smale DA, Wernberg T (2009) Satellite-derived SST data as a proxy for water temperature in nearshore benthic ecology. Mar Ecol Prog Ser 387:27-37

* Smale DA, Wernberg T (2013) Extreme climatic event drives range contraction of a habitat-forming species. Proc R Soc B 280:20122829

* Smale DA, Wernberg T, Oliver ECJ, Thomsen M and others (2019) Marine heatwaves threaten global biodiversity and the provision of ecosystem services. Nat Clim Chang 9:306-312

Strydom S, Murray K, Wilson S, Huntley B and others (2020) Too hot to handle: unprecedented seagrass death driven by marine heatwave in a World Heritage Area. Glob Change Biol 26:3525-3538

Thomsen MS, Mondardini L, Alestra T, Gerrity S and others (2019) Local extinction of bull kelp (Durvillaea spp.) due to a marine heatwave. Front Mar Sci 6:84

Underwood AJ (1997) Experiments in ecology: their logical design and interpretation using analysis of variance. Cambridge University Press, Cambridge

* Visch W, Rad-Menéndez C, Nylund GM, Pavia H, Ryan MJ, Day J (2019) Underpinning the development of seaweed biotechnology: cryopreservation of brown algae (Saccharina latissima) gametophytes. Biopreserv Biobank 17: 378-386

Vranken S, Wernberg T, Scheben A, Severn-Ellis A and others (2021) Genotype-environment mismatch of kelp forests under climate change. Mol Ecol 30:3730-3746

* Wernberg T, Smale DA, Tuya F, Thomsen MS and others (2013) An extreme climatic event alters marine ecosystem structure in a global biodiversity hotspot. Nat Clim Chang 3:78-82

Wernberg T, Bennett S, Babcock RC, de Bettignies T and others (2016) Climate-driven regime shift of a temperate marine ecosystem. Science 353:169-172

*Wernberg T, Coleman MA, Bennett S, Thomsen MS, Tuya F, Kelaher BP (2018) Genetic diversity and kelp forest vulnerability to climatic stress. Sci Rep 8:1851-1858

Wernberg T, Coleman MA, Babcock RC, Bell SY and others (2019) Biology and ecology of the globally significant kelp Ecklonia radiata. Oceanogr Mar Biol Annu Rev 57: 265-324

Wiencke C, Roleda MY, Gruber A, Clayton MN, Bischof KAI (2006) Susceptibility of zoospores to UV radiation determines upper depth distribution limit of Arctic kelps: evidence through field experiments. J Ecol 94:455-463

Submitted: March 18, 2021

Accepted: June 21, 2021

Proofs received from author(s): August 10, 2021 